\title{
Opções Teórico-Metodológicas em Pesquisas Qualitativas: Representações Sociais e Discurso do Sujeito Coletivo
}

Theoretical-Methodological Options in Qualitative Research: Social Representations and Discourse of the Collective Subject

\author{
Sebastião Junior Henrique Duarte \\ Doutorando em Enfermagem pela Escola de Enfermagem de Ribei- \\ rão Preto - Universidade de São Paulo; Docente da Faculdade de \\ Enfermagem da Universidade Federal de Mato Grosso. \\ Endereço: Av. Fernando Correa da Costa, s/n, Coxipó, CEP 78060- \\ 900, Cuiabá, MT, Brasil. \\ E-mail: sjhdळusp.br \\ Marli Villela Mamede \\ Professora Titular da Escola de Enfermagem de Ribeirão Preto \\ - Universidade de São Paulo. \\ Endereço completo: Avenida Bandeirantes, 3900, CEP 14040-902, \\ Ribeirão Preto, SP, Brasil. \\ E-mail: mavimaœeerp.usp.br

\section{Sônia Maria Oliveira de Andrade} \\ Professora Adjunta - Universidade Federal de Mato Grosso do Sul. \\ Endereço: Cidade Universitária DTA, 79070900, Campo Grande, \\ MS, Brasil. \\ E-mail: anart.msi®terra.com.br
}

\section{Resumo}

O presente estudo, de natureza bibliográfica, objetivou apresentar a Teoria das Representações Sociais e o Discurso do Sujeito Coletivo como opções teórico-metodológicas para o desenvolvimento de pesquisas em enfermagem que tomam por base o saber comum. As Representações Sociais são consideradas como saber popular, mitos, crenças, costumes, que convergem no senso comum e que são socialmente compartilhados. O Discurso do Sujeito Coletivo é uma técnica de organização do material resultante do trabalho de campo, geralmente de falas oriundas de entrevistas, questionários, papers, materiais gráficos etc. Realizou-se busca na literatura pertinente às Representações Sociais e ao Discurso do Sujeito Coletivo, de modo que pudesse contribuir com o entendimento da teoria e do método. Foram apresentados aspectos relevantes sobre tais referenciais, buscando identificar as relações entre ambos no processo de construção da realidade dos participantes, permitindo conhecer o modo como as pessoas pensam, vivem, agem, reagem e compartilham esses saberes populares. As considerações finais apontam que as Representações Sociais e o Discurso do Sujeito Coletivo são ferramentas essenciais em estudos de natureza qualitativa.

Palavras-chave: Pesquisa Qualitativa; Teoria das Representações Sociais; Discurso do Sujeito Coletivo. 


\section{Abstract}

The present bibliographical study aimed to introduce Social Representations Theory and the Discourse of the Collective Subject as theoretical-methodological options for the development of research in nursing that is based on common knowledge. Social Representations are popular knowledge, myths, beliefs, customs, which converge on common sense and are socially shared. The Discourse of the Collective Subject is a technique to organize material resulting from fieldwork, generally discourses deriving from interviews, questionnaires, papers, graphic materials, etc. A search in the literature was made regarding Social Representations and the Discourse of the Collective Subject, so as to contribute to the understanding of the theory and of the method. Relevant aspects of these frameworks were presented, aiming to identify the relations between them in the process of construction of the participants' reality. Thus, it was possible to learn about the way people think, live, act, react and share popular knowledge. The final remarks reveal that Social Representations and the Discourse of the Collective Subject are essential tools in qualitative studies.

Keywords: Qualitative Research; Social Representations Theory; Discourse of the Collective Subject.

\section{Introdução}

A prática da enfermagem, por natureza, trata de questões qualitativas por lidar com o cuidado do ser humano inserido no seu meio social. Isso porque se preocupa em apreender o modo de vida do homem, assim como suas demandas para atingir um nível ótimo de qualidade de vida. Nesse sentido, as diversidades sociais e culturais são levadas em consideração no plano de cuidado do ser humano, cujas questões costumeiramente transformam-se em motivo de estudos dada a complexidade de sua apreensão. Assim, a pesquisa qualitativa é uma modalidade que responde a questões muito particulares, tanto individual quanto coletivamente. Ela trabalha com o universo de significados, motivos, aspirações, crenças, valores e atitudes, o que corresponde a um espaço mais profundo das relações, dos processos e dos fenômenos que não podem ser reduzidos à operacionalização de variáveis matemáticas (Minayo, 2003).

0 estudo dessas questões requer o uso de teorias que organizem e validem os dados coletados, bem como exijam a aplicação de métodos que permitam a visualização clara e objetiva do material resultante do processo de coleta de dados, o qual geralmente é oriundo de entrevistas, questionários, relatos, observações, entre outros. Uma das possibilidades para a interpretação das informações colhidas, no contexto da enfermagem, é a utilização das Representações Sociais; como método de relevância na tarefa relacionada ao tratamento dos dados, o Discurso do Sujeito Coletivo se mostra adequado a esse propósito.

Para o desenvolvimento da pesquisa qualitativa, o pesquisador precisa ter clareza de que tanto os indivíduos quanto os grupos são sociologicamente regidos por uma ideologia dominante, que é produzida e imposta por sua classe social, tendo como base, principalmente, o Estado, a religião, a escola e o trabalho. As pessoas reproduzem o que aprendem nesses ambientes e tomam por importante para si, compartilhando no meio social em que estão inseridas, estabelecendo, assim, o que se chama de senso comum.

O estudo dessas representações, ou seja, das Representações Sociais, presta-se como elemento fundamental para o trabalho com a comunidade, principalmente quando se tratar de grupos vulneráveis, como o grupo de gestantes, já que a gravidez é marcada por diversas crenças, fantasias e mitos que alimentam o senso comum (Duarte, 2007). 
Nesse sentido, o presente estudo tem por objetivo apresentar a Teoria das Representações Sociais e o Discurso do Sujeito Coletivo como opções teórico-metodológicas para o desenvolvimento de pesquisas em enfermagem que tomam por base o saber popular.

\section{As Representações Sociais}

A Teoria das Representações Sociais surgiu da obra de Serge Moscovici intitulada La psychanalyse:son image et son public, publicada na França em 1961. O sociólogo Durkheim trabalhara, anteriormente, com as representações coletivas, contribuindo significativamente para a construção dessa teoria (Moscovici, 2003).

As Representações Sociais não pertencem a um único campo de conhecimento; possuem suas raízes na sociologia, atravessam a psicanálise de Freud e se desenvolvem na psicologia social de Moscovici, aprofundada por outros autores como Denise Jodelet. A partir dos anos 1960, aumenta o interesse pelo estudo dos fenômenos do domínio simbólico, importando a explicação destes como recurso às noções de consciência e imaginário. Acrescentam-se as noções de representação e memória social, que também fazem parte dessas buscas de explicação que receberão, após os anos 1980, sua teorização, passando a servir como ferramenta para outros campos, como a saúde, a educação, a didática e o meio ambiente, com propostas teóricas diversificadas (Arruda, 2002).

Definir Representações Sociais não é tarefa fácil, dada sua composição polimorfa. No entanto, adota-se a conceituação dada por Moscovici, em que se entende por Representações Sociais um conjunto de conceitos, proposições e explicações originados na vida cotidiana no desenrolar das comunicações interpessoais. Elas são equivalentes, em nossa sociedade, aos mitos e sistemas de crenças das sociedades tradicionais; podendo, também, serem vistas como a versão contemporânea do senso comum (Sá, 1996).

Para Jodelet (2002), as Representações Sociais são definidas como sendo uma forma de conhecimento socialmente elaborado e compartilhado com um objetivo prático e que contribui para a construção de uma realidade comum a um conjunto social. Elas são equivalentes aos mitos e às crenças das sociedades, ou seja, ao senso comum. Recomenda-se que a Representação Social seja estudada articulando-se elementos afetivos, mentais e sociais, integrando-os, ao lado da cognição, da linguagem e da comunicação, às relações sociais que afetam as representações e a realidade material, social e ideal sobre a qual eles vão intervir.

As Representações Sociais podem, ainda, ser definidas como modalidades de conhecimento prático orientadas para a comunicação e para a compreensão do contexto social, material e ideativo em que vivemos. São formas de conhecimento que se manifestam como elementos cognitivos (imagens, conceitos, categorias, teorias), mas que não reduzem jamais os componentes cognitivos (Spink, 1993).

As Representações Sociais devem ser vistas como uma maneira específica de compreender e comunicar aquilo que já sabemos. Elas ocupam uma posição, em algum ponto, entre conceitos que têm como objetivo abstrair o sentido do mundo e introduzir nele ordem e percepções que reproduzam o mundo de forma significativa (Moscovici, 2003).

Elas funcionam como um sistema de interpretação da realidade, atuando nas relações estabelecidas pelos indivíduos no meio em que estão inseridos, orientando, assim, seus comportamentos e práticas. Embora as Representações Sociais não determinem inteiramente as decisões tomadas pelos indivíduos, elas limitam e orientam o universo de possibilidades colocadas a sua disposição (Vergara e Ferreira, 2005).

Destaca-se que as Representações Sociais, por meio da atividade psíquica, dão às coisas uma nova forma. Elas envolvem uma relação entre o sujeito e o objeto-mundo. $\mathrm{O}$ sujeito se insere numa comunidade concreta e simbólica, embora não esteja condenado a simplesmente reproduzir essa realidade. 0 indivíduo está constantemente elaborando uma tensão entre o mundo e seus próprios esforços para ser um sujeito. É nesse processo de construção de sua identidade social que ele se desenvolve, ou seja, na relação entre sujeito e mundo social, que é mediada pelas Representações Sociais. Ao mesmo tempo em que o sujeito recria a realidade social e suas representações, também modifica a sua própria relação com o mundo. Dessa forma, os objetos presentes no meio social aparecem sob a forma de representação, constantemente recriados pelos sujeitos (Siman, 2005).

As Representações Sociais, segundo Moscovici (2003), não são as mesmas para todos os membros da sociedade, pois elas dependem tanto do conhecimento 
do senso comum (popular) como do contexto sociocultural em que os indivíduos estão inseridos.

No caso de novas situações ou diante de novos objetos, o processo de representar apresenta uma sequência lógica: tornar familiares objetos desconhecidos (novos) por meio de um duplo mecanismo então denominado amarração - "amarrar um barco a um porto seguro", conceito que logo evoluiu para "ancoragem” - e objetivação, processo pelo qual indivíduos ou grupos acoplam imagens reais, concretas e compreensíveis, retiradas de seu cotidiano, aos novos esquemas conceituais que se apresentam e com os quais têm de lidar (Oliveira, 2004).

O processo de objetivação elucida como se estrutura o conhecimento do objeto e possui três etapas. Primeiramente, o indivíduo seleciona e descontextualiza os elementos daquilo que vai representar, enxugando as informações. Estas se fragmentam com base no conhecimento prévio sobre o objeto, na experiência e em nossos valores. Então, recosturam-se os fragmentos de informações de modo a tornarem-se o centro figurativo das representações. Esses caminhos levam ao núcleo da representação, ou seja, o objeto que era misterioso foi então destrinchado e recomposto, tornando-o objetivo e palpável, adquirindo assim um sentido natural. Essa fase de naturalização é a etapa final da objetivação. 0 processo de ancoragem é o modo pelo qual o conhecimento se enraíza no social e retorna a ele, e é por meio do qual se dá sentido ao objeto (Moscovici, 2003).

Em síntese, a Representação Social pode ser compreendida como um processo social da dialética (comunicação e discurso). As Representações Sociais são vistas como atributos pessoais, como estruturas de conhecimento individuais, embora compartilhadas. Esse compartilhamento refere-se a crenças, imagens, metáforas e símbolos num grupo, comunidade, sociedade ou cultura (Wagner, 200o).

Nessa perspectiva, as Representações Sociais são entendidas como um conteúdo mental estruturado, ou seja, cognitivo, avaliativo, afetivo e simbólico a respeito de um fenômeno social relevante, tomando a forma de imagens ou metáforas, sendo compartilhado com os demais membros do grupo social de modo consciente.

Nesse processo, o sujeito busca o que lhe é familiar para fazer uma conversão daquilo que é novidade e participa com os demais membros do grupo ou sociedade em que está inserido, legitimando comportamentos, atitudes, crenças e valores (Jodelet, 2002).
A aplicação e utilização das Representações Sociais como referencial teórico no campo da pesquisa em enfermagem têm favorecido a identificação de conhecimentos peculiares a objetos de estudos em saúde, os quais têm contribuído para a compreensão e estruturação de comportamentos e ações frente a determinados fatos relacionados ao processo saúde-doença.

Considerando que a formação das Representações Sociais se dá quando as pessoas discutem e argumentam entre si o seu cotidiano, seus mitos, sua herança histórica e cultural, a teoria das Representações Sociais tem permitido aos pesquisadores em enfermagem identificar vários aspectos psicológicos e socioculturais envolvidos em muitos eventos em saúde enquanto conhecimentos elaborados pelos sujeitos sociais em consonância com a realidade em que estão inseridos (Guareschi e Jovchelovitch, 1995).

\section{Discurso do Sujeito Coletivo}

Sua origem ocorreu na década de 1990, onde os autores Lefèvre e Lefèvre realizaram uma pesquisa com servidores públicos da cidade de São Paulo com o objetivo de conhecer a opinião destes sobre o Programa de Gerenciamento Integrado, proposto durante a gestão Pinotti na Secretaria da Saúde de São Paulo. Diante dos dados coletados, observou-se que as respostas eram muito semelhantes, diferindo em alguns critérios, embora não mudando o resultado.

O processamento desses discursos em um único discurso do grupo social em análise deu origem ao Discurso do Sujeito Coletivo, que posteriormente recebeu as figuras metodológicas que o transformaram em referencial metodológico, sendo utilizado em pesquisas qualitativas que têm depoimentos como base.

O DSC é uma técnica de construção do pensamento coletivo que visa revelar como as pessoas pensam, atribuem sentidos e manifestam posicionamentos sobre determinado assunto. Trata-se de um compartilhamento de ideias dentro de um grupo social. Entende-se por discurso todo posicionamento argumentado. O Discurso do Sujeito Coletivo é um espelho coletivo. É como se as pessoas se olhassem e, a partir daí, tomassem consciência de como são (Lefèvre e Lefèvre, 2005).

Metodologicamente o discurso do sujeito coletivo é uma proposta de organização e tabulação de dados qualitativos de natureza verbal, obtidos de depoimen- 
tos, artigos de jornal, matérias de revistas semanais, cartas, papers, revistas especializadas etc. Para sua construção são utilizadas como figuras metodológicas as expressões-chave, as ideias centrais e as ancoragens (Lefèvre e Lefèvre, 2005).

São utilizados trechos do discurso, ou seja, descrições literais dos depoimentos, reveladores da essência do conteúdo das representações, os quais são denominados expressões-chave. A partir dos recortes de fala significativos identificam-se as ideias centrais que se constituem de palavras ou expressões linguísticas que revelam, de maneira precisa e sintética, o sentido presente nos depoimentos.

Organizam-se, em mapas denominados Instrumentos de Análise do Discurso (IAD), as expressões-chave, as ideias centrais e as ancoragens. As expressões-chave exemplificadoras de ideias centrais semelhantes são organizadas de forma lógica e coerente, compondo um discurso único redigido na primeira pessoa do singular: o Discurso do Sujeito Coletivo (Lefèvre e Lefèvre, 2005).

No caso de surgirem depoimentos contraditórios a respeito de uma mesma questão, são elaborados DSC para as falas concordantes e para as falas discordantes.

As expressões-chave são pedaços ou trechos de material (discurso) que formam descrições literais dos depoimentos, revelando a essência do conteúdo das representações ou das teorias subjacentes a estas. As expressões são parte essencial da análise e constituem os recortes do discurso (entrevistas, questionários, jornais etc.).

A ideia central é o nome ou expressão linguística que revela e descreve, de maneira sintética e precisa, o sentido presente nos depoimentos. Descreve o sentido usando as palavras do entrevistado, não constituindo interpretação. As ideias centrais são elaboradas pelo pesquisador diante do discurso do entrevistado utilizando a fala que as indicam "fortemente". É preciso um critério que justifique a ideia central. A partir daí, o pesquisador faz uma síntese daquilo que foi justificado.

As ideias centrais servem para agrupar o discurso, podendo haver numa mesma fala mais que uma ideia central; todas elas devem ser consideradas separadamente e trabalhadas no processo de categorização.

O processo de ancoragem, de acordo com a técnica do DSC, é a manifestação de uma teoria, ideologia ou crença que os autores do discurso professam e acreditam. É uma afirmação genérica do enunciador do discurso para enquadrar uma situação específica.

A ancoragem deve ser sempre uma afirmação redigida positivamente. Os valores estão embutidos na fala, na crença. Trata-se do valor forte que está no grupo.

A ancoragem não necessariamente está respondendo à pergunta, enquanto as ideias centrais devem respondê-la. Portanto, a ancoragem traz a ideia básica que sustenta o discurso, ou seja, na fala deve conter o que a pessoa expressa e acredita. É por meio das ideias básicas que se identificam as Representações Sociais sobre o objeto em apreensão, o que está contido no senso comum sobre aquilo que está sob estudo. Portanto, é preciso haver marcas discursivas que representem o grupo, marcadores de generalização: "tudo", "qualquer", "quem".

O processo final da técnica do DSC é a elaboração da síntese, ou seja, trata de fazer a reunião: utilizando discurso único redigido na primeira pessoa do singular, expressões-chave que apresentam ideias centrais ou ancoragens semelhantes.

À medida que os DSC vão sendo construídos, compõem-se o sistema de interpretação da realidade pelos participantes, as relações estabelecidas por eles no contexto social, bem como vão se colocando em relevo seus comportamentos e práticas.

Nesse processo de construção dos DSC, os cenários sociais se apresentam enriquecidos de Representações Sociais, nos quais as práticas se mostram organizadas. É através desse espelho coletivo que o pesquisador tem às suas mãos uma riqueza de informações que lhe auxiliará na condução do plano de cuidado à saúde.

\section{Instrumento de Análise de Discurso}

Para facilitar o processo de construção do DSC sugere-se a utilização de um modelo de instrumento de análise de discurso (IAD) que auxilia na organização das figuras metodológicas para posterior confecção do Discurso do Sujeito Coletivo.

O quadro 1 apresenta um exemplo de estudo que objetivou conhecer os motivos maternos para a não adesão ao pré-natal, o qual foi adotado na Teoria das Representações Sociais como referencial teórico, e o Discurso do Sujeito Coletivo para organização e análise dos dados. Dentre os motivos apresentados pelas gestantes, foi possível construir quatro DSC: 1 - a não 
realização do pré-natal é devido ao serviço de saúde; 2 - a não realização do pré-natal é devido ao desinteresse; 3 - a não realização do pré-natal é por sentir vergonha; 4 - a não realização do pré-natal é devido a problemas pessoais.
A identificação do sujeito se dá de acordo com os critérios estabelecidos pelo pesquisador (nomes, números, cores etc.), respeitando-se o sigilo e o anonimato das pessoas pesquisadas.

\section{Quadro I - Ilustrativo da aplicação do Instrumento de Análise de Discurso/IAD em gestantes sobre motivos para não realização do pré-natal *}

\begin{tabular}{|c|c|c|c|}
\hline Sujeito & Expressões-chave & Idéias centrais & Ancoragens \\
\hline 7 & $\begin{array}{l}\text { "... eu gosto de prestar a assistência pré-natal, sinto } \\
\text { satisfação em lidar com gestantes. Toda mulher grávida } \\
\text { que sente-se acolhida adere ao acompanhamento pré- } \\
\text { natal, independente de ser com enfermeiro ou outro } \\
\text { profissional que a assista...". }\end{array}$ & \multirow[t]{2}{*}{$\begin{array}{l}\text { Gosta de prestar } \\
\text { assistência pré-natal. }\end{array}$} & \multirow[t]{2}{*}{$\begin{array}{l}\text { Toda mulher } \\
\text { acolhida adere ao } \\
\text { pré-natal. }\end{array}$} \\
\hline 12 & $\begin{array}{l}\text { "... uma das ações de enfermagem que mais me } \\
\text { agradam é o pré-natal...". }\end{array}$ & & \\
\hline 17 & $\begin{array}{l}\text { "... nunca tive segurança em fazer pré-natal, sei lá. } \\
\text { Acho que faltou oportunidade para que eu pudesse } \\
\text { treinar mais. Tenho receio desse tipo de assistência...". }\end{array}$ & $\begin{array}{l}\text { I- insegurança para } \\
\text { prestar assistência pré- } \\
\text { natal } \\
2 \text { - falta de treinamento }\end{array}$ & Não há. \\
\hline
\end{tabular}

*Fonte: Duarte e colaboradores, 2009.

As categorias para análise e construção do Discurso do Sujeito Coletivo são estabelecidas a partir da identificação, nos instrumentos de análise de discurso, das expressões-chave, ideias centrais e ancoragens correspondentes.

Após a organização e divisão das expressões-chave, de acordo com as ideias centrais, redige-se o discurso do sujeito coletivo, considerando-se não a ordem sequencial dos sujeitos, mas a coerência interna das palavras que comporão o discurso do sujeito coletivo, conforme exemplo:

\section{Ideia Central: gosta de prestar assistência pré-natal}

“... uma das ações de enfermagem que mais me agradam é o pré-natal... gosto de prestar a assistência pré-natal, sinto satisfação em lidar com gestantes. Toda mulher grávida que sente-se acolhida adere ao acompanhamento pré-natal, independente de ser com enfermeiro ou outro profissional que a assista...".

No exemplo apresentado, o discurso inicia-se pela fala do sujeito 12 seguido do 7 , e assim por diante.

O uso da Teoria das Representações Sociais, assim como do Discurso do Sujeito Coletivo, é uma possibili- dade de aplicação nas pesquisas qualitativas e permite conservar o contexto em que a pesquisa foi realizada. Ambos são ferramentas importantes que auxiliam o pesquisador no sentido do estudo, com o mínimo de interferência.

\section{Considerações Finais}

Este artigo buscou apresentar a Teoria das Representações Sociais e o Discurso do Sujeito Coletivo como opções teórico-metodológicas para o desenvolvimento de pesquisas em enfermagem que tomam por base o saber popular. Foi visto que a Teoria das Representações Sociais tem se mostrado um referencial teórico de importância no campo da pesquisa em enfermagem, favorecendo a aplicação clínica dos resultados uma vez que o cuidado do ser humano inserido em seu contexto social é o seu objeto de trabalho. Por outro lado, a utilização do Discurso de Sujeito Coletivo como método sistemático de tratamento e análise dos dados, em pesquisas fundamentadas nas Representações Sociais, permite maior objetividade e confiabilidade no processo interpretativo dos dados de uma pesquisa qualitativa, além de favorecer a construção de discur- 
sos que representam as vozes do grupo de indivíduos sob estudo. Portanto, a teoria e o método apresentados são relevantes para a enfermagem considerando as múltiplas possibilidades de suas aplicações no meio científico.

O método do DSC pode produzir dados de alta qualidade quando convenientemente e cuidadosamente manipulado. Embora o método tenha inúmeros desafios, muitos deles fáceis de se vencer, a sua utilização em novos estudos e em situações variadas no campo da saúde auxiliará na produção mais eficiente e efetiva de pesquisas qualitativas.

A alternativa de associar a Teoria das Representações Sociais com a técnica do Discurso do Sujeito Coletivo no campo da pesquisa em enfermagem deve ser considerada.

\section{Referências}

ARRUDA, A. Teoria das representações sociais e teorias de gênero. Cadernos de Pesquisa, Rio de Janeiro, n. 117, p. 127-47, nov. 2002.

DUARTE, S. J. H. Representação social da gestante residente no Marabá a respeito do pré-natal, Campo Grande, MS. 2007. 84 p. Dissertação (Mestrado em Saúde Coletiva) Universidade Federal de Mato Grosso do Sul, Campo Grande, 2007.

DUARTE, S. J. H.; ANDRADE, S. M. O.; MAMEDE, M. V. Maternal decision on obtaining prenatal care: a study in Brazil. Midwifery, 2009. [Epub ahead of print]

GUARESCHI, P. A.; JOVCHELOVITCH, S. Textos em representações sociais. 2. ed. Petrópolis: Vozes, 1995

JODELET, D. Representações sociais: um domínio em expansão. Rio de Janeiro: Eduerj, 2002.
LEFÈVRE, F.; LEFÈVRE, A. M. C. O discurso do sujeito coletivo: um novo enfoque em pesquisa qualitativa (desdobramentos). 2. ed. Caxias do Sul: Educs, 2005.

MINAYO, M. C. S., et al. Pesquisa social. 22. ed. Petrópolis: Vozes, 2003.

MOSCOVICI, S. Representações sociais:

investigações em psicologia social. Petrópolis: Vozes, 2003 .

OLIVEIRA, M. S. B. S. Representações sociais e sociedades: a contribuição de Serge Moscovici. Revista Brasileira de Ciências Sociais, v. 19, n. 55, p. 180-6, jun. 2004.

SÁ, C. P. Núcleo central das representações sociais. Petrópolis: Vozes, 1996.

SIMAN, L. M. C. Representações e memórias sociais compartilhadas: desafios para os processos de ensino e aprendizagem da história. Cadernos Cedes, Campinas, v. 25, n. 67 p.. 348-364, set./dez 2005.

SPINK, M. J. P. O conceito de representação social na abordagem psicossocial. Cadernos de Saúde Pública, Rio de Janeiro, v. 9 n. 3, p. 300-8, jul./set.1993.

VERGARA. S. C; FERREIRA, V. C. P. Representação social de ONGs segundo formadores de opinião do município do Rio de Janeiro. Revista de Administração Pública, Rio de Janeiro, v. 39, n. 5, p. 1137-59, set./out. 2005 .

WAGNER, W. Sócio-gênese e características das representações sociais. In: MOREIRA, A. S. P.; OLIVEIRA, D. C. (Orgs.). Estudos interdisciplinares de representação social. 2. ed. Goiânia: A.B., 200o. p. $3-25$. 